\title{
Development of Vasoactive Intestinal Peptide mRNA Rhythm in the Rat Suprachiasmatic Nucleus
}

\author{
Yuriko Ban, ${ }^{1}$ Yasufumi Shigeyoshi, ${ }^{2}$ and Hitoshi Okamura ${ }^{2}$ \\ ${ }^{1}$ Department of Ophthalmology, Kyoto Prefectural University of Medicine, Kyoto 602, Japan, and 2Department of \\ Anatomy and Brain Science, Kobe University School of Medicine, Kobe 650, Japan
}

\begin{abstract}
Development of the daily rhythm of vasoactive intestinal peptide (VIP) mRNA in the rat suprachiasmatic nucleus (SCN), a main locus of circadian oscillation, was investigated by in situ hybridization. The phenotypic expression of VIP neurons occurred in two developmental stages in the ventrolateral portion of the SCN (VLSCN): the first was found before birth in the rostral part, and the second occurred in the main part between postnatal day $(\mathrm{P}) 10$ and $\mathrm{P} 20$. The latter period coincided with the time that the massive VIP-efferent fibers project to the subparaventricular zone. In the adult and P20, the VIP mRNA signals of the SCN showed a clear diurnal rhythm with a trough in the light phase and a peak in the dark phase under light/dark (LD) conditions, but under constant dark (DD) conditions, no
\end{abstract}

VIP mRNA fluctuations were observed. At P10, however, it was found that SCN VIP mRNA showed a peak at the transition from night to day and a trough at early dark period in LD conditions, in sharp contrast to the night peak in the adult rhythm. In DD conditions, a light-phase peak and a dark-phase trough were also observed at P10, contrasting the arrhythmic feature at adult stage. The present findings suggest that daily VIP rhythm was first generated in the early developed clock-controlled rostral SCN neurons, and later regulated by light-dependent main VLSCN neurons.

Key words: suprachiasmatic nucleus; vasoactive intestinal peptide; in situ hybridization; development; circadian rhythm
The hypothalamic suprachiasmatic nucleus (SCN) contains a circadian oscillator that is involved in behaviors and hormonal secretion in mammals (Moore, 1983). The rat SCN contains many peptidergic neurons, of which vasoactive intestinal peptide (VIP) neurons are restricted to the ventrolateral portion of the SCN (VLSCN) (Card et al., 1981). The VLSCN receives innumerable photic signals from the retinal ganglion cells directly through the retinohypothalamic tract (RHT) (Hendrickson et al., 1972; Moore and Lenn, 1972) or indirectly through the geniculohypothalamic tract (GHT) (Swanson et al., 1974). Photic information conveyed by these pathways entrains the circadian clock to an environmental light/dark time schedule (Meijer and Rietveld, 1989). VIP neurons in the VLSCN receive synaptic contacts by both the direct (Ibata et al., 1989) and indirect (Hisano et al., 1988) pathways, and it is known that VIP gene expression is negatively regulated by the photic stimuli (Takahashi et al., 1989; Albers et al., 1990; Okamoto et al., 1991). Because the light-evoked rhythms disappear under constant dark (DD) conditions and the VIP level decreased in proportion to the duration of light exposure (Shinohara et al., 1993), the expression of VIP is driven not by an endogenous circadian clock, but rather by the photic information, when the adult SCN was examined.

However, there is much evidence that VIP expresses its own

Received Nov. 25, 1996; revised Jan. 24, 1997; accepted Feb. 27, 1997.

This work was supported in part by grants from the Kanehara-Ichiro Memorial Foundation, the Ciba-Geigy Foundation, and the Ministry of Education, Science, Sports, and Culture of Japan. We thank Dr. Y. Ibata (Kyoto Prefectural University of Medicine) for his support and encouragement throughout the experiment. We also thank Dr. S-I.T. Inouye (Yamaguchi University) for critical reading of this manuscript, Dr. T. Inatomi for the preliminary experiment, and Dr. N. Yanaihara for donating anti-VIP serum.

Correspondence should be addressed to Dr. Hitoshi Okamura, Department of Anatomy and Brain Science, Kobe University School of Medicine, 7-5-1 Kusunokicho, Chuo-ku, Kobe 650, Japan.

Copyright $\odot 1997$ Society for Neuroscience $\quad 0270-6474 / 97 / 173920-\bullet \$ 05.00 / 0$ endogenous rhythm after surgical or pharmacological manipulations of the SCN afferents. The serotonin depletion by intraperitoneal injection of parachlorophenylalanine, an inhibitor of the rate-limiting enzyme of serotonin synthesis, induced endogenous VIP rhythm independent of photic cues in DD-conditioned rats (Okamura et al., 1995). Serotonergic inputs from the midbrain raphe nuclei are another major input to the VLSCN (Moore et al., 1978), and synapse with VIPergic neurons (Kiss et al., 1984; Bosler and Beaudet, 1985). Similar light-independent endogenous VIP rhythms were detected in somatostatin-depleted cysteaminetreated rats (Fukuhara et al., 1994) and in slice cultures of the SCN in vitro (Shinohara et al., 1994). To explain these phenomena, we hypothesized previously that synaptic inputs from various VLSCN afferents inhibit the endogenous rhythm of VIP under normal conditions, and that the elimination of these synaptic inputs liberates the endogenous rhythm. In the present study, we investigated the VIP mRNA rhythm at various developmental stages, during which the invasion of nerve afferents and the formation of synaptic contacts are rapidly occurring. In the SCN, the first retinal terminals arrive at the last embryonic stage (Bunt et al., 1983), prominent synaptogenesis occurs between postnatal day (P) 4 and P10 (Moore and Bernstein, 1989), and rapheserotonergic and GHT-neuropeptide Y (NPY) afferents increase between P10 and P20 (Takatsuji et al., 1995). Taking these developmental data into account, we analyzed the development of the daily rhythm of VIP mRNA level by semiquantitative in situ hybridization, with special reference to the site of expression of VIP phenotype in the VLSCN.

\section{MATERIALS AND METHODS}

Animals. Pregnant female Wistar rats (Nihon Animal Care, Osaka, Japan) were obtained at 7-10 d of gestation (timed pregnancy). They were maintained in individual cages under the standard laboratory conditions with diurnal lighting (light on at 7:00 A.M., light off at 7:00 P.M.) and free 
access to food and water. These rats typically gave birth on the 22 nd day after mating. The day after mating was designated embryonic day (E) 1. To study the fetuses, pregnant females were anesthetized with pentobarbital (Nembutal, $70 \mathrm{mg} / \mathrm{kg}$ ), and the fetuses were removed and perfused. The fetuses were anesthetized by deep low-temperature anesthesia. The time of birth was carefully noted, and the day after birth was designated P1. All postnatal animals were anesthetized with ether before being killed. We used fetuses of both sexes, but only male postnatal rats.

For the developmental immunocytochemical study, E17 animals were used $(n=3)$, as well as E18 $(n=3), \mathrm{E} 19(n=2), \mathrm{E} 20(n=3), \mathrm{E} 22(n=$ 2), P1 $(n=5), \mathrm{P} 5(n=5), \mathrm{P} 10(n=5), \mathrm{P} 20(n=5)$, and P50 (adult; $n=$ 5) animals. For the developmental in situ hybridization histochemistry experiments, animals were used at E17 $(n=3), \mathrm{E} 18(n=3), \mathrm{E} 19(n=$ $2)$, E20 $(n=2), \mathrm{E} 22(n=2), \mathrm{P} 1(n=5), \mathrm{P} 5(n=5), \mathrm{P} 10(n=5), \mathrm{P} 20$ $(n=5)$, and P50 (adult; $n=5)$.

For the quantitative developmental analysis of the in situ hybridization signals, animals at P1, P5, P10, P20, and P50 (5 rats per group) were killed at Zeitgeber time (ZT) 4 (4 hr after the onset of the light phase; ZT0 was defined as the transition time from the dark to light phase) under the standard LD conditions.

The daily rhythm of the VIP mRNA signals was also analyzed in P10, P20, and P50 rats. After 2 weeks of adaptation to the standard light/dark cycles, half of the rats $(n=30$ at each developmental stage) were transferred to DD conditions before being subjected to experiments on the third day in constant darkness. The rest of the animals were kept under LD cycles. In these experiments, circadian time (CT) 0 and CT12 are referred to as 7:00 A.M. and 7:00 P.M., respectively, because locomotor activity measurements indicated that $2 \mathrm{~d}$ of free running in darkness did not shift the phase of the animals' rhythm by $>0.5 \mathrm{hr}$ (data not shown). The animals were killed for in situ hybridization at ZT0, ZT4, ZT8, ZT12, ZT16, and ZT20 for the LD entrained rats, and at CT0, CT4 ( $4 \mathrm{hr}$ after the onset of the third subjective day), CT8, CT12, CT16 (4 hr after the onset of the third subjective night), and CT 20 for the DD free-running rats. The dams were purchased before partum, four to five male pups were chosen, and these litters were nursed for $10-20 \mathrm{~d}$. The dams were also associated with their litters until they were killed.

The experimental protocol of the current research was approved by the Committee for Animal Research at Kobe University School of Medicine and the Kyoto Prefectural University of Medicine.

Immunocytochemistry. Under deep ether anesthesia, animals at E17, E18, E19, E20, E22, P1, P5, P10, P20, and P50 were perfused via the left cardiac ventricle with $200 \mathrm{ml}$ of $0.1 \mathrm{M}$ phosphate buffer (PB) containing $4 \%$ paraformaldehyde and $0.2 \%$ picric acid. The brains were then removed and post-fixed in the same fixative solution for $2 \mathrm{~d}$. Serial frontal sections (thickness: $60 \mu \mathrm{m}$ for embryonic animals, $40 \mu \mathrm{m}$ for postnatal animals) from the rostral end of the SCN to the retrochiasmatic area were made on a cryostat. The sections were incubated with an anti-VIP serum (code no. R5302; courtesy of Dr. N. Yanaihara, Yanaihara Institute; diluted 1:5000 with $1 \% \mathrm{~PB}$ containing $0.3 \%$ Triton $\mathrm{X}-100)$ at $4^{\circ} \mathrm{C}$ for $3 \mathrm{~d}$. They were then incubated with biotinylated anti-rabbit IgG (1:1000, Vecta) at $4^{\circ} \mathrm{C}$ overnight and an avidin-biotin-peroxidase conjugate (1: 1000 , Vecta) at $4^{\circ} \mathrm{C}$ overnight. The immunoreactions were visualized in $0.05 \mathrm{M}$ Tris- $\mathrm{HCl}$ buffer, $\mathrm{pH} 7.5$, containing $0.02 \% 3,3^{\prime}$-diaminobenzidine tetrahydrochloride and $0.003 \% \mathrm{H}_{2} \mathrm{O}_{2}$. The reaction was stopped by the transfer of the sections into $0.05 \mathrm{M}$ Tris- $\mathrm{HCl}$ buffer. The specificity of the antisera used has been described elsewhere (Yanaihara et al., 1977; Okamura et al., 1986, 1987). The sections were mounted onto chromealum-coated slides, air-dried, cleared in a graded series of ethanol, cleared in xylene, and then mounted in Entellan (Merck, Darmstadt, Germany).

In situ hybridization. Under deep ether anesthesia, animals at E17, E18, E19, E20, E22, P1, P5, P10, P20, and P50 were perfused via the left cardiac ventricle with $\mathrm{PB}$ containing $4 \%$ paraformaldehyde. The brains were removed, post-fixed in the same fixative for $12 \mathrm{hr}$ at $4^{\circ} \mathrm{C}$, and transferred into $20 \%$ sucrose in PB for $24 \mathrm{hr}$. Frontal sections ( $40 \mu \mathrm{m}$ in thickness) were made using a cryostat, collected into $4 \times \mathrm{SSC}$, and then processed for in situ hybridization as described previously (Okamura et al., 1995). Briefly, the sections were treated with $0.1 \mathrm{mg} / \mathrm{ml}$ proteinase $\mathrm{K}$

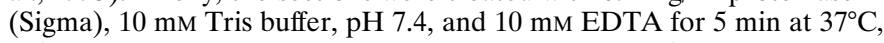
$4 \%$ paraformaldehyde in $0.1 \mathrm{M} \mathrm{PB}$ for $5 \mathrm{~min}$, and $0.25 \%$ acetic anhydride in $0.1 \mathrm{M}$ triethanolamine for $10 \mathrm{~min}$. The sections were then incubated in hybridization buffer [ $50 \%$ formamide, $0.025 \%$ yeast tRNA, $0.025 \%$ herring sperm DNA, $1 \times$ Denhardt's solution $(0.02 \%$ Ficoll $/ 0.02 \%$ polyvinyl pyrolidone $/ 0.02 \%$ bovine serum albumin), $1 \%$ Saccosyl, $100 \mathrm{~mm}$ dithiothreitol, $600 \mathrm{~mm} \mathrm{NaCl}$, and $60 \mathrm{~mm}$ sodium citrate] containing the ${ }^{35} \mathrm{~S}$ -
dATP-labeled oligonucleotide probe complementary to the rat VIP mRNA for $12 \mathrm{hr}$ at $42^{\circ} \mathrm{C}$. The nucleotide sequence of the probe complementary to the rat VIP mRNA (Nishizawa et al., 1985) was 5'GTCGCTGGTGAAAACTCCATCAGCATGCCT

GGCATTTCTGGA-3' (42-mer) (a gift from Dr. S-I.T. Inouye, Yamaguchi University). The probe was $3^{\prime}$ end-labeled using $\left[{ }^{35} \mathrm{~S}\right] \mathrm{dATP}(6000$ $\mathrm{Ci} / \mathrm{mm}$; New England Nuclear) and terminal deoxynucleotidyl transferase (Takara Shuzo, Kyoto, Japan), and was used at a final concentration of $3.2 \times 10^{6} \mathrm{dpm} / \mathrm{ml}$. To elucidate the time difference in the VIP mRNA signals of the SCN, we hybridized sections from six different time points in the same chamber. After hybridization, these sections were rinsed in $2 \times \mathrm{SSC} / 50 \%$ formamide for $15 \mathrm{~min}$ four times, and in $1 \times \mathrm{SSC}$ for $30 \mathrm{~min}$ twice at $42^{\circ} \mathrm{C}$. The sections were mounted onto gelatin-coated microscope slides, air-dried, and dehydrated through a graded alcohol series. The slides were exposed to an imaging plate (radiosensitive plates coated with BaFBr:Eu ${ }^{2+}$; Fuji Film) for $24 \mathrm{hr}$, after which the slides were apposed to $\beta$-max film (Amersham International) at $4^{\circ} \mathrm{C}$ for $4 \mathrm{~d}$. The $\beta$-max films were developed by a Kodak D19 developer for $5 \mathrm{~min}$ at $20^{\circ} \mathrm{C}$. The section-mounted slides were dipped in Kodak NTB2 nuclear track emulsion (dilution 1:1 distilled water), developed after 12 weeks, and counterstained by Nissl staining (cresyl violet).

VIP mRNA-positive cells were counted in each rostrocaudally arranged SCN section ( $40 \mu \mathrm{m}$ in thickness) in a representative rat at each stage (P10, P20, and adult). By Nissl staining, SCN was recognized as the small, compactly packed cell mass located bilaterally just dorsal to the optic chiasma. Most rostral SCN sections judged by the Nissl were designated as No. 1 , and the following sections were sequentially numbered at the rostrocaudal direction.

Quantification of the signals and statistical analysis. To quantify the VIP mRNA signals, the radioactivity of each SCN on the imaging plate was measured as photo-stimulated luminescence (PSL) emitted from the imaging plate when scanned with a laser beam, and was analyzed using a microcomputer interfaced to an image analyzing system (BAS2000; Fuji Film). In this system, a wide range of linearity was established between the isotope radioactivity and the PSL signals (Amemiya and Miyahara, 1988). The total radioactivity count of the sections is considered proportional to the amount of VIP mRNA present. The number of PSL signals in the preoptic area of each section was zero. The PSL values of the SCN in each rat were summed from the most rostral to the caudal end. In the study of the VIP mRNA signals in the SCN at each developmental stage, signals at each developmental point were expressed as mean $\pm \operatorname{SEM}(n=$ 5). Statistical analyses of the data were made by using one-way ANOVA followed by Scheffe's multiple comparisons test. In the study of the daily rhythm of VIP mRNA signals at P10, P20, and P50, the average of the VIP signals was estimated at each developmental stage $(n=5)$. At each time point, the value was expressed as a percentage of the average VIP mRNA level and as mean $\pm \operatorname{SEM}(n=5)$, which was also statistically analyzed by one-way ANOVA followed by Scheffe's multiple comparisons test.

\section{RESULTS}

\section{Macroautoradiographic analysis of the development of VIP mRNA in the SCN}

At E17, no VIP mRNA was detected in the forebrain, including the SCN. VIP mRNA signals first appeared in the SCN at E18 (Fig. 1). At this stage, the signals were very weak, but the signal intensity increased until E21, at which point distinct signals were detected in the SCN.

After birth, VIP mRNA signals increased progressively in density and intensity. We semiquantified the VIP mRNA increase by summing the SCN sections in each rat at different developmental stages using an image analyzing system (Fig. 2). Until P5, the PSL value was less than one-tenth of the adult value. The increase became pronounced from $\mathrm{P} 5$ to $\mathrm{P} 10$, and the sharpest increase in VIP mRNA was observed between P10 and P20. By P20, the signal intensity had reached the adult level.

\section{VIP rhythm in the SCN in late neonatal (P10), weaning (P20), and adult stages (P50)}

The image analyzing system (BAS2000; Fuji Film) for quantifying VIP mRNA signals in the present study has a wide range of 

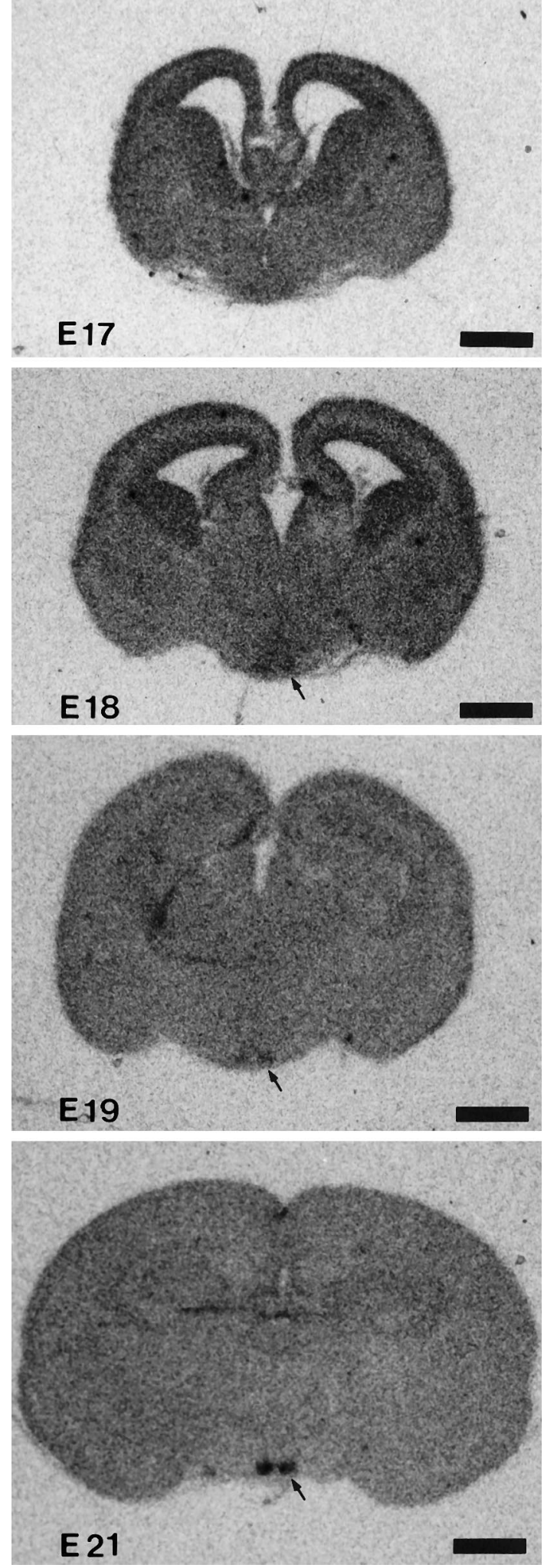

Figure 1. In situ hybridization of VIP mRNA in the prenatal period. Photomicrographs were taken from $\beta$-max film. Scale bar, $1 \mathrm{~mm}$.

linearity between isotope radioactivity and PSL signals, but the resolution sensitivity is not very high. Thus, daily variations in the weak signals (e.g., at P5; one-tenth of the adult value) could not be examined by this system. Therefore, we analyzed rats only at P10 (late neonatal period) and P20 (weaning stage), comparing those at P50 (adult).

In the adult SCN under LD conditions, the VIP mRNA signals showed a clear diurnal rhythm: a trough during the early light phase (ZT4) and a gradual increase until the early night phase (ZT16), followed by a gradual decrease (Fig. 3). The VIP mRNA levels showed diurnal variations in adult stage (ANOVA, $F_{(5,24)}=5.486$, $p<0.01)$. In the adult SCN under DD conditions, no VIP mRNA fluctuations were observed (ANOVA, $F_{(5,18)}=0.53, p>0.5$ ).

VIP mRNA signals in P20 rats also showed a diurnal rhythm under LD conditions: a peak at ZT20 and a trough at ZT4 (ANOVA, $F_{(5,24)}=3.607, p<0.05$ ) (Fig. 3). However, the amplitude was smaller than in the adult. In P20 rats under DD conditions, the mean values at each time point varied widely, but they do not represent a statistically significant difference $\left(\right.$ ANOVA, $\left.F_{(5,24)}=1.565, p>0.2\right)$.

P10 rats also showed the diurnal rhythm under LD conditions $\left(\right.$ ANOVA, $\left.F_{(5,12)}=9.570, p<0.01\right)$. Surprisingly, the phase of the rhythm was completely different from the adult and P20 rats. P10 rats showed a peak at the onset of the light phase (ZT0) and a trough $4 \mathrm{hr}$ after the onset of the dark phase (ZT16) (Fig. 3). Moreover, we found that under DD conditions, the VIP mRNA showed a rhythm; the VIP mRNA levels showed a peak at the early subjective day (CT4) and a trough at the early subjective night $(\mathrm{CT} 16)\left(\mathrm{ANOVA}, F_{(5,18)}=3.783, p<0.05\right)$.

\section{Cellular analysis of the VIP neurons in the developing SCN}

One day later (E19) or on the same day (E18) of the first appearance of the VIP mRNA signals, VIP-immunoreactive neurons appeared in the VLSCN (data not shown). At this stage, weakly immunoreactive cell bodies with faintly immunopositive fibers were restricted to the ventral border of the VLSCN, and no immunoreactive materials were found in the dorsomedial part or outside of the SCN. From E21 to P1, the number of immunoreactive cell bodies and proximal processes increased, and a few processes had reached the dorsomedial part of the SCN (Fig. 4B). Rarely, solitary fibers were detected in the paraventricular thalamic nucleus and the retrochiasmatic area (data not shown). At P5, the VIP immunoreactivity and mRNA signals had increased, but their pattern of distribution in the VLSCN was basically similar. However, a moderate number of VIP-immunoreactive fibers were found in the dorsomedial part of the SCN, and sparse SCN-efferent VIP fibers to the anterior hypothalamic area were detected at this stage (data not shown).

The distinctive feature of the distribution pattern of VIP neurons in the SCN at these perinatal stages is that the area of VIP distribution was very narrow; the positive immunoreactivity and mRNA signals were restricted in the medial part of the VLSCN (Fig. 4A3, $A 4, D, E$ ), extending ventral thin wings in a lateral direction (Fig. $4 D$, double thin arrows). Thus, most of the VLSCN neurons did not show VIP phenotype. The adult-type distribution showing the positive signals throughout the whole VLSCN was found only in the most rostral section.

To examine the anatomical correlation with the age-dependent changes in the VIP mRNA rhythm, we performed a more detailed morphological analysis of VIP gene-expressing cells in the SCN at P10 (late neonatal period) and P20 (weaning stage), and compared those at P50 (adult) in serial in situ hybridization sections (40 $\mu \mathrm{m}$ thickness). In Nissl staining, SCN was distinguished easily by the surrounding anterior hypothalamic area by a landmark of the dense accumulation of small, packed cells. In rostrocaudally 


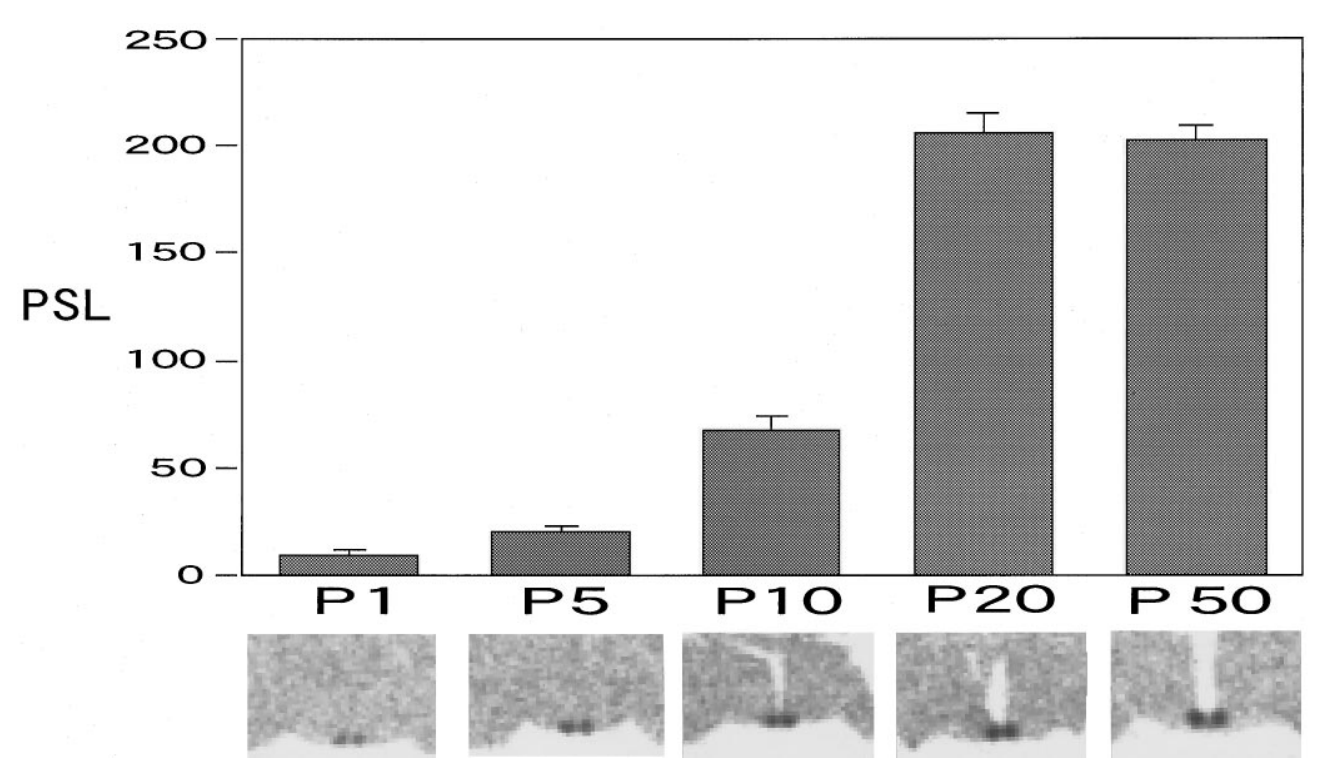

Figure 2. Postnatal development of VIP mRNA levels shown as the total amount of PSL on imaging plates. The data are shown as the mean \pm SEM, and examples of the images are shown under the time schedule.

ordered Nissl-stained sections, VIP mRNA-positive cells were first found in the second or third section from the rostral head of the SCN at all stages examined (see Fig. 6).

At P10, in the rostral level of the nucleus (Fig. 5, P10, numbers 1 and 2), strong VIP mRNA signals were evenly found in the whole region of VLSCN. This whole VLSCN distribution pattern was found in the only two serial sections (i.e., $80 \mu \mathrm{m}$ thickness), but after those (Fig. 5, P10, number 3), there was a tendency for the medial VIP signal intensity to be higher than the lateral half of the VLSCN. In the middle sections (Fig. 5, P10, numbers 4 and 5 ), the signal level decreased suddenly, and a signal was confined to the medial part (Fig. 5, $M M$ ) with no labeling in the lateral part (Fig. 5, ML). In the caudal sections (Fig. 5, P10, numbers 6 and 7), the signal was also sparse.

The VIP mRNA distribution changed dramatically between P10 and P20. At P20, the sections showing the whole VLSCN distribution pattern increased in number (rostral four sections, i.e., $160 \mu \mathrm{m}$ thickness; Fig. 5, P20, numbers 1, 2, 3, and 4). A slight mediolateral distribution tendency was observed at the next section (Fig. 5, P20, number 5), and this tendency is more pronounced in the two subsequent sections (Fig. 5, P20, numbers 6 and 7 ). However, in contrast to P10 rats, it should be noted that the level of signals in these middle-level sections did not decrease. In the caudal sections (Fig. 5, P20, numbers 8 and 9 ), the signal level clearly decreased.

VIP mRNA signals in adults were found in the whole VLSCN in most of the SCN sections (Fig. 5, ADULT, numbers 1, 2, 3, 4, 5,6 , and 7 ), and the mediolateral gradient was only found in caudal two sections (Fig. 5, ADULT, numbers 8 and 9). The level of signal intensity was high throughout the SCN. The development of the VIP mRNA is schematically summarized in horizontal plane as Figure $8 A$.

The above tendency was confirmed by the count of VIP mRNApositive cell number in each rostrocaudally ordered section (Fig. 6). In Nissl staining, SCN was detected from number 1 to number 14 at P10, number 1 to number 16 at P20, and number 1 to number 17 at adult. From the most rostral section (number 1) to the number 5 sections, VIP cell number was similar at each stage, but after the number 6 sections, the P10 stage shows a completely different pattern compared with other stages; VIP cell number concomitantly decreased after number 6 at P10, but the high levels of cell number were observed until number 11 and number 12 sections at $\mathrm{P} 20$ and adult. The total cell number of the SCN in each developmental stage was 352 (P10), 682 (P20), and 835 (adult).

Immunocytochemical analyses were also performed in P10, P20, and adult rats. Compared with P1 rats, the innervation of VIP-stained fibers to the dorsomedial part of the SCN had greatly increased by $\mathrm{P} 10$ (Fig. $7 A$ ), and the immunoreactive density was about the same as the $\mathrm{P} 20$ and adult rats (Fig. $7 C, E$ ). However, at $\mathrm{P} 10$, the extra-SCN dorsal projections were weak, and very few projections were observed in the subparaventricular zone (Watts and Swanson, 1987) just ventral to the paraventricular nucleus (Fig. 7B). At P20, the VIP-efferent projections to the subparaventricular zone had increased dramatically and reached the adult level (Fig. 7D,F).

\section{DISCUSSION}

In the present study, we demonstrated that VIP mRNA showed an endogenous (light-independent) circadian rhythm in the early postnatal period (P10), and the conversion to the adult-type light-dependent rhythm took place between P10 and P20. The finding seems to be consistent with the presence of the two ontogenetically different VIP neuronal cell groups in the SCN; the first starts to be expressed before birth, and the second between $\mathrm{P} 10$ and P20.

\section{Rhythm of VIP expression in the SCN}

In the adult stage, we found that VIP mRNA signals in the SCN showed a night-peak and day-trough type of diurnal rhythm in LD conditions, whereas no VIP mRNA fluctuations were observed under DD conditions. The result is consistent with previous reports at the peptide (Albers et al., 1987; Takahashi et al., 1987, 1989; Morin et al., 1991; Shinohara et al., 1993) and mRNA levels (Gozes et al., 1989; Albers et al., 1990; Okamoto et al., 1991; Yang et al., 1993). In the present study, we also found that VIP gene expression was regulated by light at the weaning stage (on P20) as it was in adults; the VIP mRNA signals under LD conditions showed a peak at dark phase and a trough at light phase, but no rhythm was found in DD conditions.

P10 rats also showed a diurnal rhythm under LD conditions. However, in contrast to the adult and P20 rhythms, the result of 

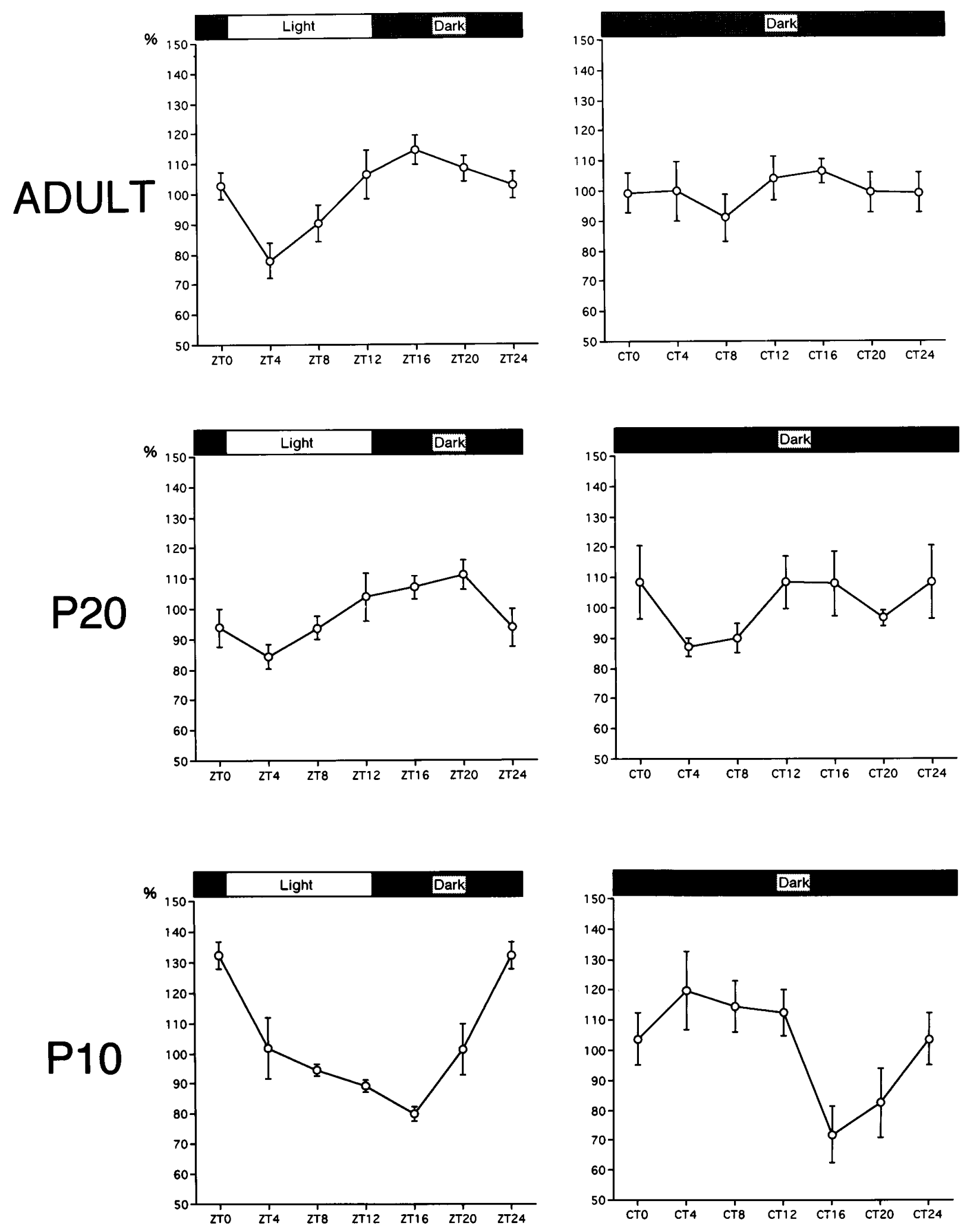

Figure 3. Diurnal and circadian profiles of VIP mRNA levels in the SCN at P10, P20, and adult (P50).

analysis on P10 animals showed a peak at the onset time of the light phase, and a trough in early dark phase. Moreover, on P10 even under DD conditions, the VIP mRNA level in the SCN demonstrated a clear circadian rhythm with a peak on the early subjective day and a trough on the early subjective night. The peaks in the subjective day and troughs in the subjective night resemble the reported deoxyglucose uptake rhythm (Schwartz et al., 1980), electrical activity rhythm (Inouye and Kawamura, 1979, 


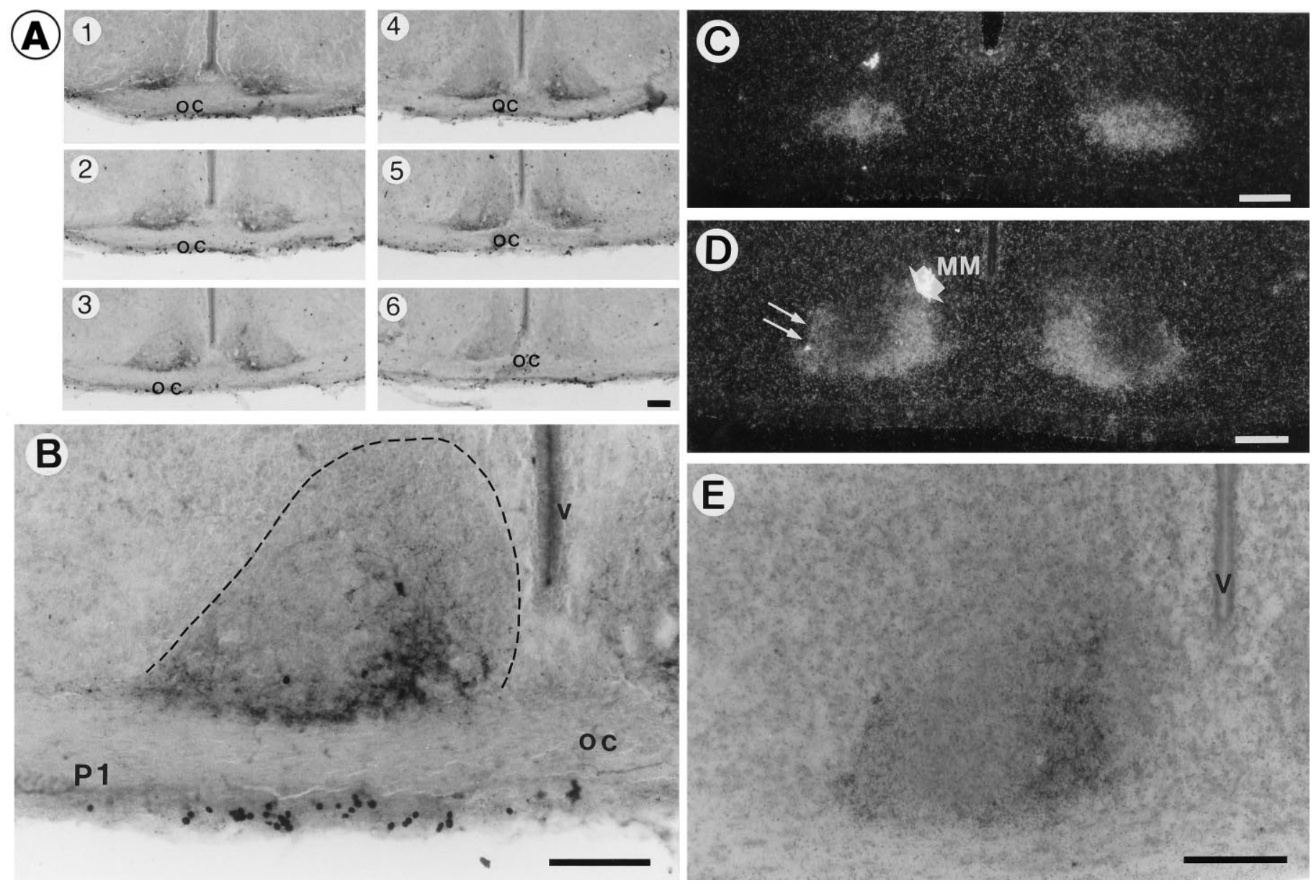

Figure 4. Immunocytochemistry $(A, B)$ and emulsion images of in situ hybridization $(C-E)$ of VIP at P1. $A$, Rostrocaudal arrangement of VIP immunoreactivity in the SCN. Note that immunoreactivities were distributed not in the whole part, but only in limited areas of the VLSCN in most sections. $B$, Higher magnification photomicrograph of $A 3$. Boundaries of $\mathrm{SCN}$ at $\mathrm{P} 1$ are encircled with dotted lines. $C, D$, Dark-field photomicrographs of VIP mRNA at the most rostral $(C)$ and the middle $(D)$ level of the SCN. At the middle level of the VLSCN, the signal mass was detected in the main medial $(M M)$ part (thick short arrow), extending ventral thin wings to the lateral part (thin long arrows). E, Bright-field higher magnification photomicrograph of $D$ counterstained with cresyl violet. $o c$, Optic chiasma; $v$, third ventricle. Scale bars, $100 \mu \mathrm{m}$.

1982), and vasopressin rhythm at both the peptide (Tominaga et al., 1992) and mRNA (Cagampang and Inouye, 1994) levels in the SCN. The current observation suggests that VIP mRNA level at $\mathrm{P} 10$ is under the influence of the circadian clock.

Previously, we hypothesized that VIP gene expression in the SCN may be regulated by synaptic inputs from outside the $\mathrm{SCN}$, and that the elimination of these extrinsic factors might reveal the endogenous VIP rhythm, from the in vivo evidence of the overt endogenous rhythm in DD-conditioned serotonergic afferent-omitted rats (Okamura et al., 1995) and in vitro data of rhythmic VIP release in long incubated SCN slice culture (Shinohara et al., 1994). Our present results seem to fit this speculation. For synaptogenesis in the SCN, Moore and Bernstein (1989) reported that synaptic contacts were rare in the E21 to P2 stages, but that they increased strikingly from P4 to P10, and by P10, the number of synapses was approximately $70 \%$ of the total synaptic number in adults. At P10, many of the synaptic types found in adults were found (Moore and Bernstein, 1989), but it should be noted that some types of synapses were rare at this point (i.e., small pleomorphic synapses with densely stained presynaptic terminals containing large densecore vesicles, perhaps including the peptidergic ones, and axosomatic synapses, indicating inhibitory synapses). Synaptic diversity and the complexity of the neuropile continued for up to 5 weeks (Lenn et al., 1977). For the development of optic nerve innervation in the SCN, Güldner (1978) reported that optic nerve terminals containing characteristic tubular mitochondria made synapses first at P9, and these optic synapses increased and matured from P17 to P27. Thus, it is evident that synaptic contacts are not complete at $\mathrm{P} 10$, and our results can be interpreted to suggest that late-forming synapses may be important for the suppression of the endogenous VIP rhythm. If this is the case, then it could be speculated that VIP shows an endogenous rhythm in younger animals. VIP mRNA first appeared at E18 in the SCN and increased progressively thereafter, which was consistent with the previous developmental studies using in situ hybridization and peptide immunocytochemistry (Ishikawa and Frohman, 1987; Hares and Foster, 1988; Laemle, 1988). However, the levels at E18 to P5 were less than one-tenth of the adult rat mRNA levels. Unfortunately, our present quantitative analysis using the macroautoradiographic imaging plates fails to adequately detect such low-level expression of VIP mRNA in these perinatal animals. More sensitive and quantitative methods might reveal the VIP rhythm at an earlier neonatal stage. 


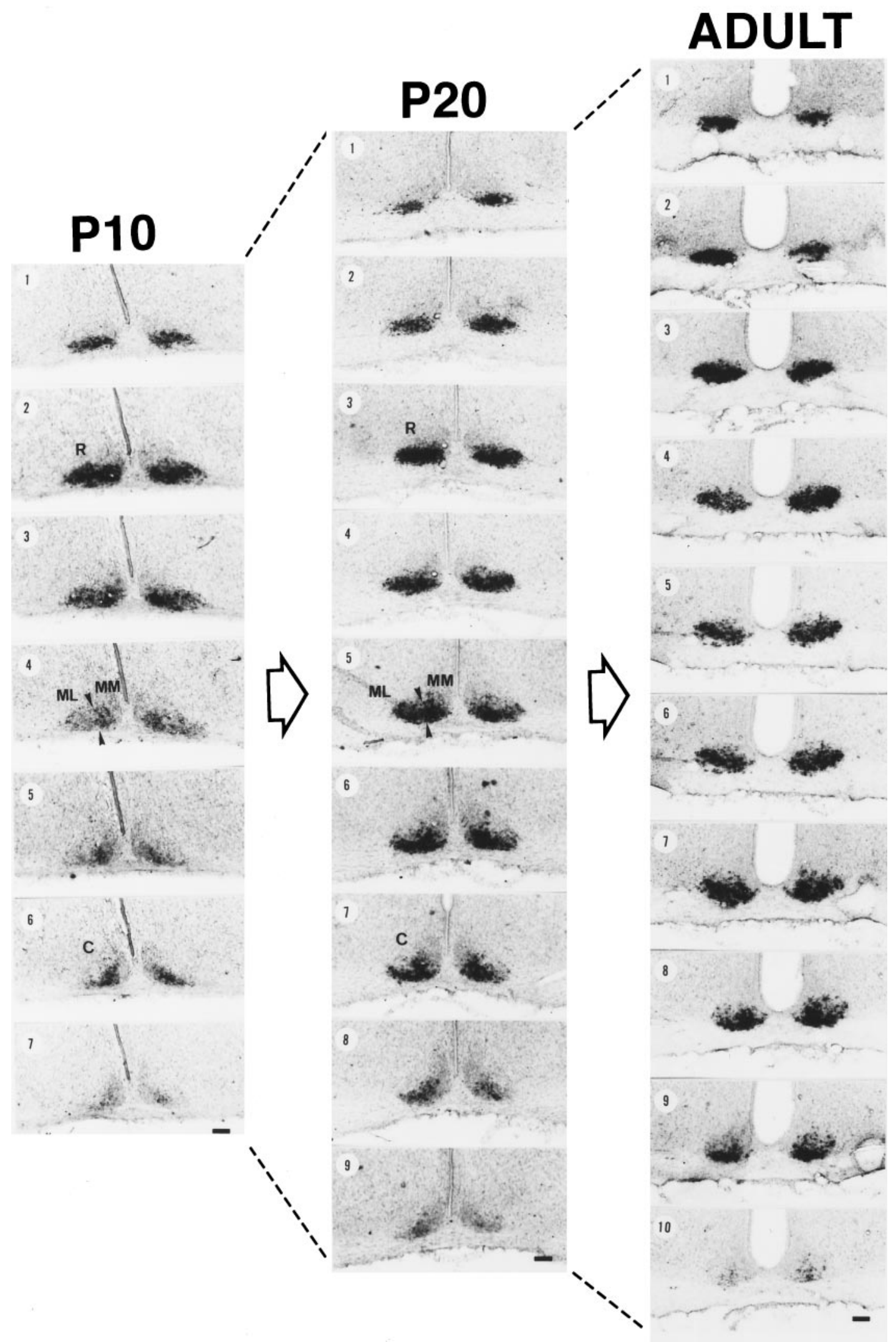

Figure 5. Emulsion images of VIP mRNA in the SCN at P10, P20, and adult (P50). All serial sections (40 $\mu \mathrm{m}$ thickness) from one rat at each stage are presented in order of rostrocaudal direction. At middle-level sections (P10, number 4; P20, number 5) of P10 and P20, VLSCN was subdivided further into lateral (middle-lateral; $M L)$ and medial (middle-medial; $M M)$ parts, and the borders of MM and ML are presented as arrowheads. $(R)$ and $(C)$ are representative sections of rostral and caudal SCN, respectively. Scale bars, $100 \mu \mathrm{m}$. 
Figure 6. Counts of VIP mRNA-positive cells in each rostrocaudally arranged section in one representative rat at each stage (P10, P20, and adult). Section 1 was designated as the most rostral SCN section recognized by Nissl staining, and the section number was sequentially ordered at the rostrocaudal direction. Section thickness was $40 \mu \mathrm{m}$ at all stages.

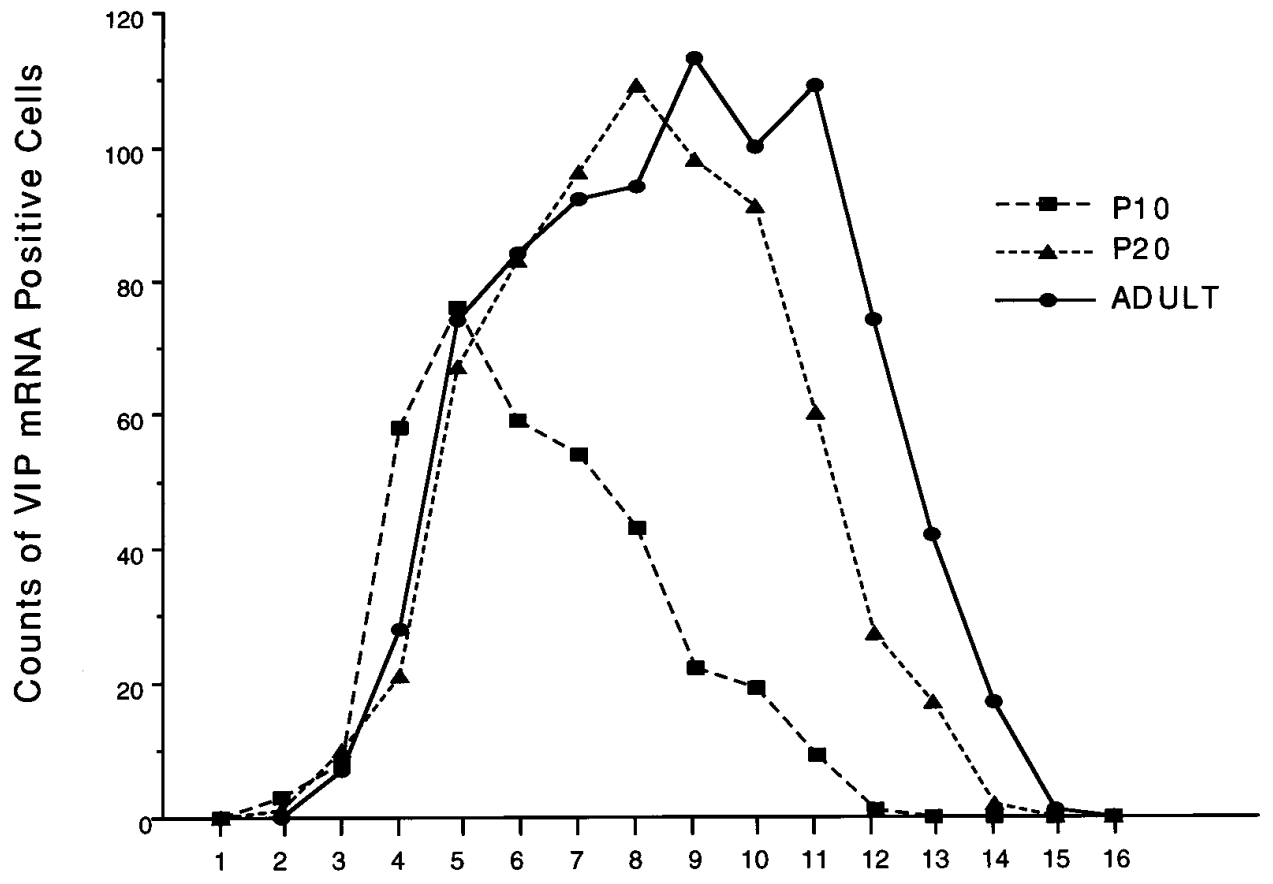

Section Number

\section{Two VIP neuronal hypotheses and the conversion of the endogenous rhythm to the light-dependent rhythm}

In the present study, we found that VIP phenotype expression occurs in the SCN in two steps: the first appeared in the fetal period in the rostral VLSCN, and the second occurs later, mainly between $\mathrm{P} 10$ and $\mathrm{P} 20$ in the main portion of the VLSCN (Fig. $8 A$ ). The delayed appearance of VIP mRNA phenotypes in the main portion of the nucleus may have several explanations based on neurogenesis, neuronal migration, and phenotypic expression. $\left[{ }^{3} \mathrm{H}\right]$ Thymidine autoradiography suggested that the neurogenesis of rat SCN neurons started at E14 and ended at E17 (Ifft, 1972; Altman and Bayer, 1978). Thus, the later appearance of VIP mRNA expression is not attributable to neurogenesis. The possibility of the migration of VIP neurons from the rostral VLSCN to the main part of VLSCN cannot be excluded at present. However, even if it could occur, the migration alone cannot explain the increase in the total cell number at P20, which was two times as much as that at P10, and this difference cannot be explained without assuming the appearance of newly differentiated VIP mRNA-positive cells in the SCN (particularly in the VLSCN).

What factors then trigger the phenotypic expression of neurons in the main VLSCN? One possibility is that the innervation from other brain structures trigger the phenotypic expression of VIP neurons (Fig. $8 B$ ). It is generally accepted that the neurons produced from the final mitotic division of progenitor cells need environmental factors to express its phenotype (Anderson, 1989). Genetic expression of specific genes is known to be regulated by a number of neurotrophic factors, and it is known that neurotransmitters, in addition to their mediation of transsynaptic information coding, can induce a spectrum of effects on neuronal outgrowth, plasticity, and survival (Lauder, 1993). In this context, it is interesting that the first timing of NPY and serotonergic innervation to the SCN (Takatsuji et al., 1995) coincides with the period of late phenotypic expression of VIP in the main part of
VLSCN (Fig. 8B). Retinal fibers may not have a direct effect on this conversion, because the first retinal innervation was already detected before birth and concomitantly increased until P20 (Bunt et al., 1983; Takatsuji et al., 1995). However, it is possible that the optic synaptic formation influences the maturation, because the most prominent time of the increase of optic synapses was between P12 and P17 (Güldner, 1978).

The demonstration of two developmentally different VIP neuronal groups in the VLSCN may explain the conversion of VIP rhythms occurring from P10 to P20. The endogenous rhythm generated by the early developed rostral VLSCN VIP neurons is later taken over by the light-dependent rhythm generated by the late-developed main VLSCN VIP neurons controlled by the inputs conveying external time cues. Do the rostral VIP VLSCN neurons still keep the endogenous rhythmic expression at the adult stage? The answer is not yet known, because we failed to remove and analyze the rostral VLSCN group, since in the adult rat, rostral VLSCN and main VLSCN VIP neurons are tightly packed and distributed in continuity. It also is not known whether undifferentiated main VLSCN neurons before P10 have the ability to produce an endogenous rhythm, because in our experiments they were analyzed only after the expression of VIP mRNA.

The demonstration of endogenous rhythms in the neonatal period suggests that VIP neurons play a role as a circadian oscillator, at least in early developmental life. It should be noted that the existence of VIP neurons in grafts correlates with the restoration of circadian locomotor activity in a transplantation experience using fetal SCN cells (Silver et al., 1990; Lehman et al., 1991). A slice culture study showing the endogenous VIP release also used SCN tissues from neonatal animals (Shinohara et al., 1994). It is interesting to note that those studies use SCN tissue at the early developmental stage, when SCN contains only the early developed endogenous rhythmic VIP cells, without having lateforming light-dependent VIP cells. The endogenous rhythm of 


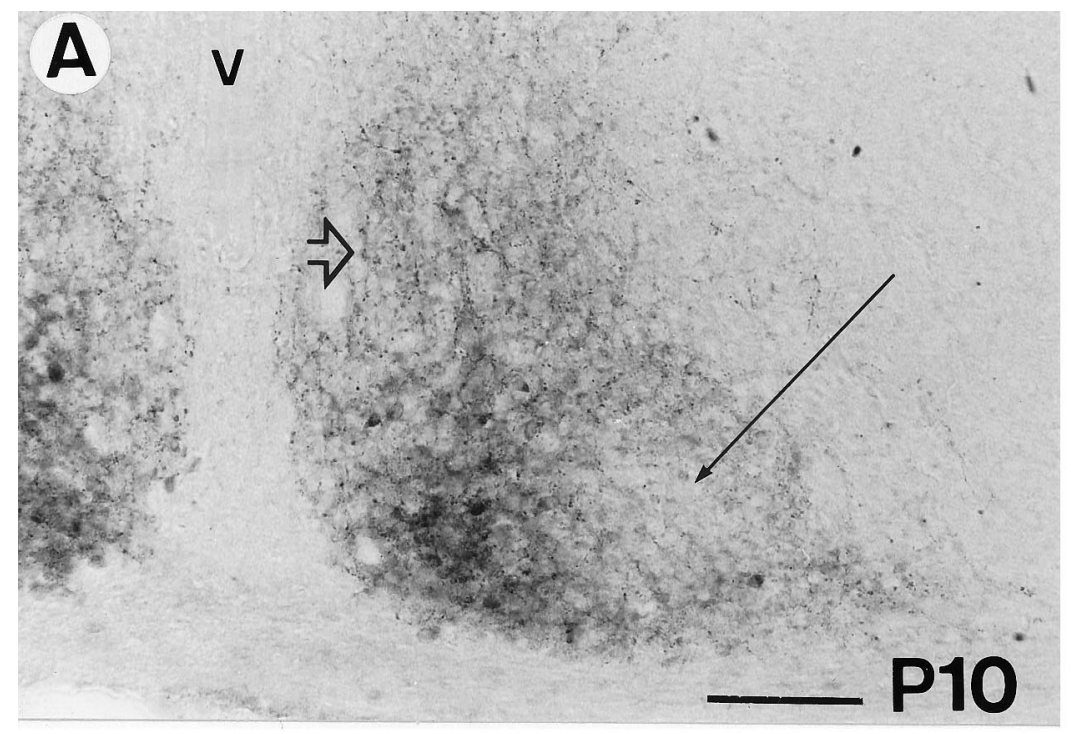

B
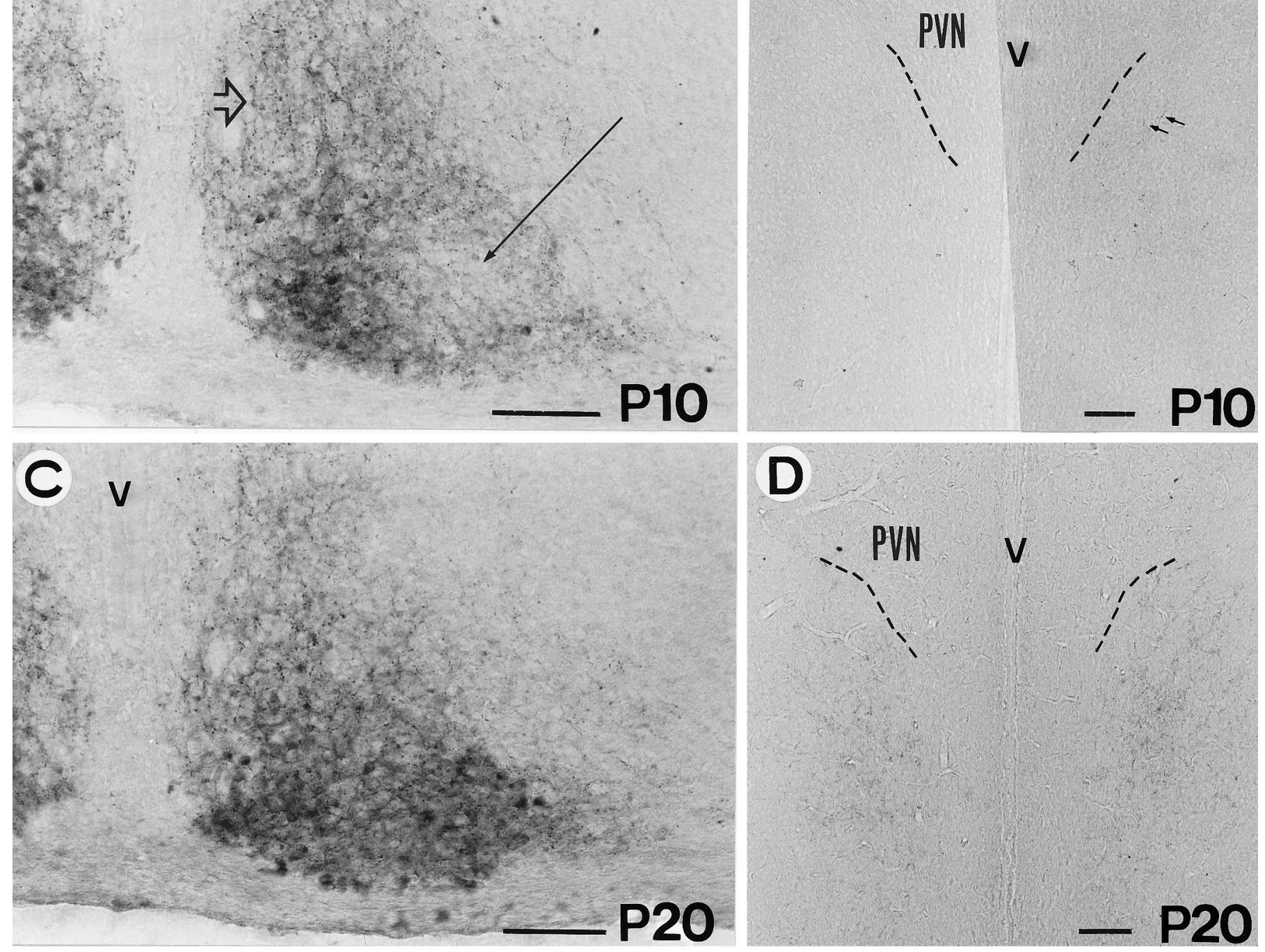

\section{D}
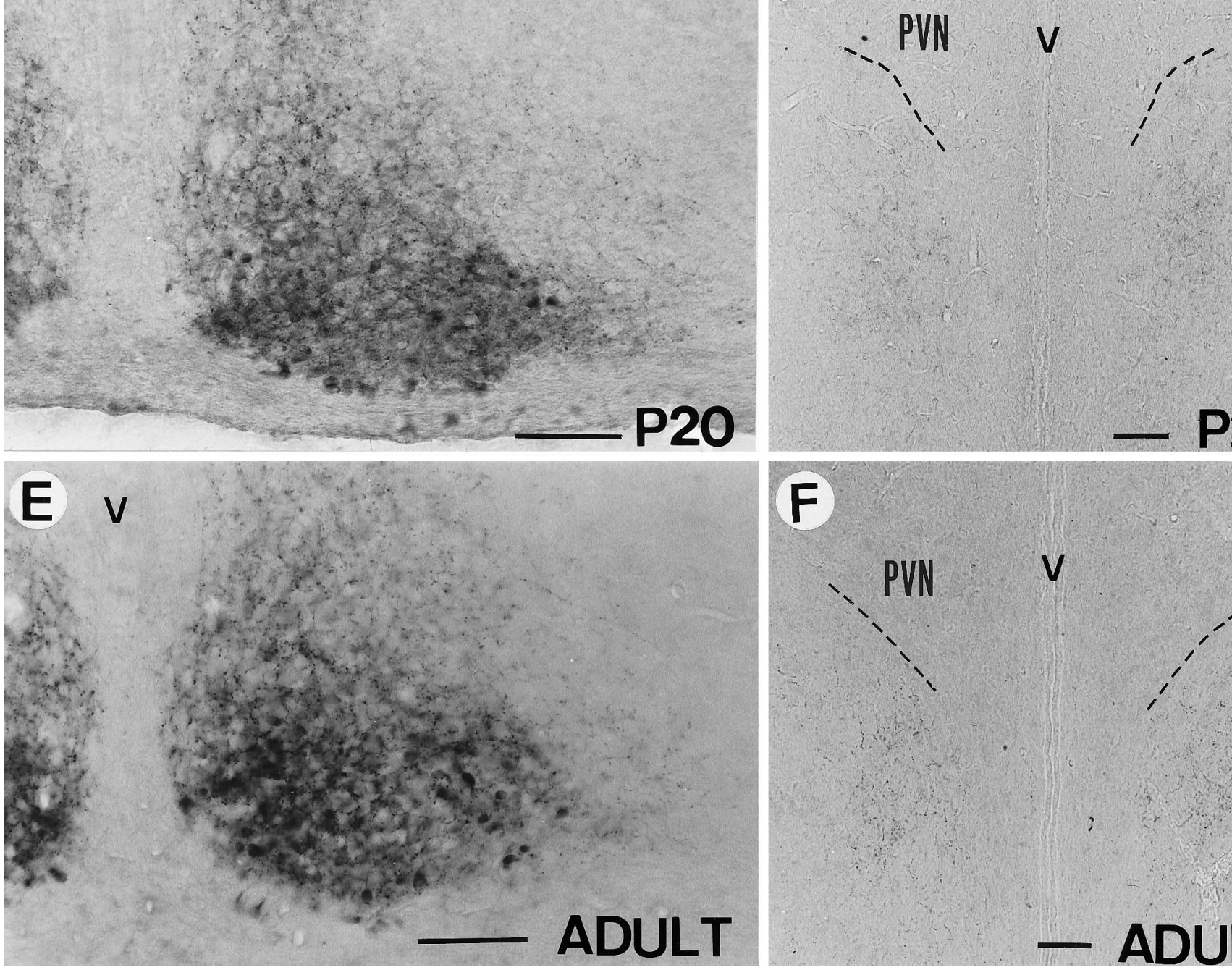

F
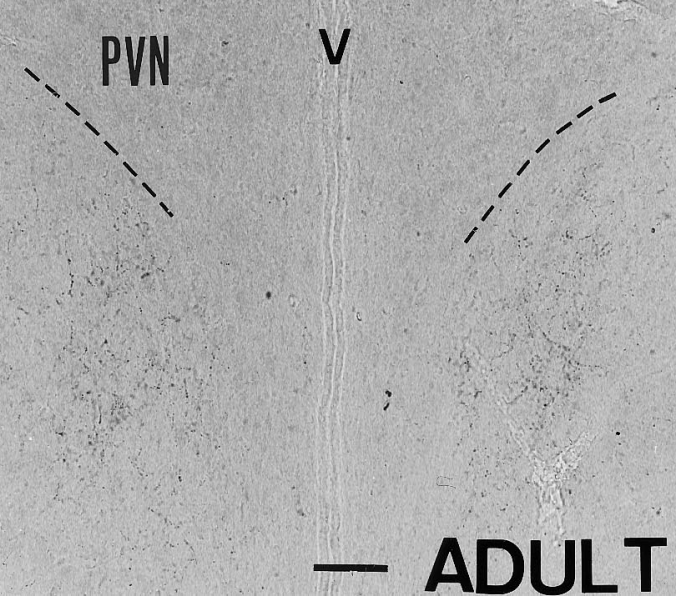

Figure 7. Immunocytochemistry of VIP at $\mathrm{P} 10(A, B), \mathrm{P} 20(C, D)$, and adult (P50) $(E, F)$ in $\mathrm{SCN}(A, C, E)$ and the subparaventricular zone $(B, D, F)$. A long thin arrow indicates the main portion of the VLSCN, and a thick hollow arrow indicates the dorsomedial part of the SCN. PVN, Hypothalamic paraventricular nucleus; $v$, third ventricle. Scale bars, $100 \mu \mathrm{m}$. 

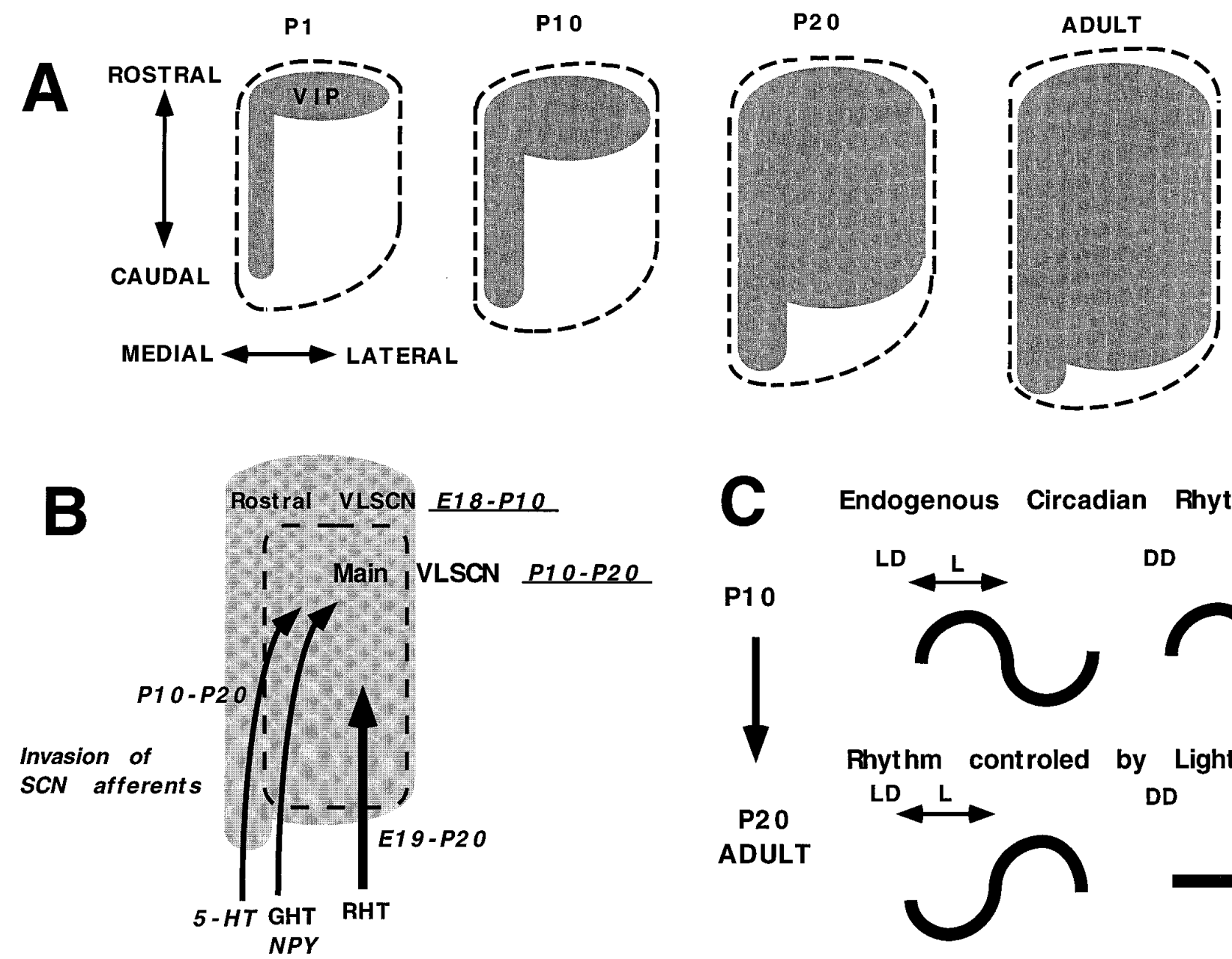

\section{Endogenous Circadian Rhythm}

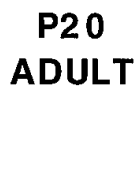

DD
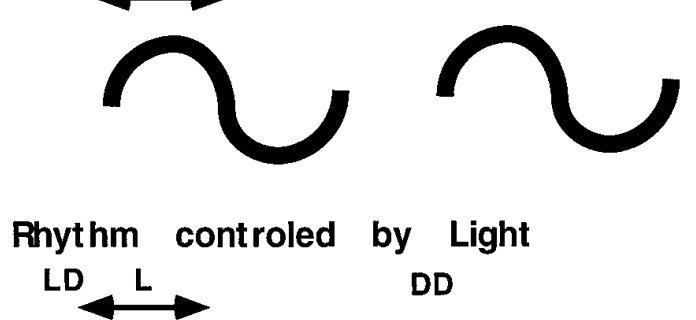

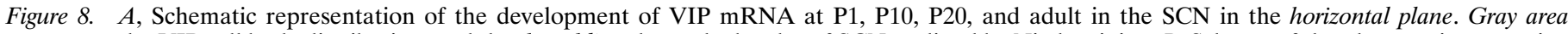

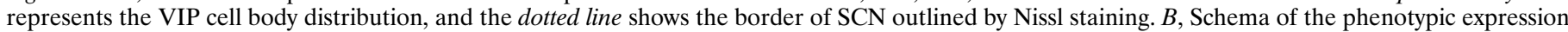

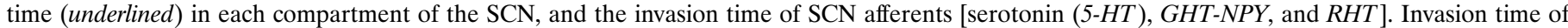

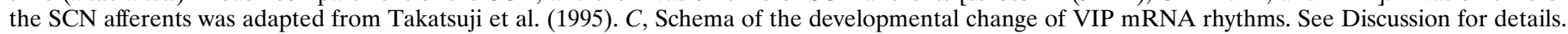

VIP in rats developed in total darkness from birth (Glazer and Gozes, 1994) also might be attributable to the undifferentiation of the main VLSCN VIP neurons.

Immunocytochemical analysis showed that the fiber density of the dorsomedial part of the SCN was low at P1 and reached the adult level at P10. Because the formation of intra-SCN VIP fiber plexus appeared complete by P10, it is possible that the early formed rostral VLSCN neurons are involved mostly in the intraSCN communication. However, the projection of VIP efferents to other brain areas was not established until P10. SCN has efferent projections to the various parts of the brain, but according to Watts et al. (1987), the most intensive projection was to the subparaventricular zone, a part of the anterior hypothalamic and medial preoptic areas. By immunocytochemistry, many authors have shown that the majority of efferents of SCN VIP neurons terminate to this area (Watts, 1991; Okamura and Ibata, 1994). Because the increasing period of VIP innervation to the subparaventricular zone coincides with the appearance of VIP neurons in the main VLSCN, it is possible that the majority of VIP efferents occurs from main VLSCN neurons, unlike the rostral VLSCN neurons which are intrinsic.

The efferent projection of late-forming VIP neurons can be related to the development of behavioral and hormonal rhythms.
It is known that the entrainment of circadian locomotor activity to the environmental light/dark cycle was first observed between P10 and P14 (Honma and Hiroshige, 1977). Circadian fluctuation of plasma corticosterone was observed in the third to fourth week of postnatal days (Takahashi et al., 1979; Hiroshige et al., 1982). These findings suggest that the circadian oscillating signals remained disconnected from the locomotor center or the hormone regulating center until $\mathrm{P} 10$. In support of these findings, the present study demonstrates that the primary VIP efferents from SCN to the subparaventricular zone, from which many outputs transmitted to most brain areas (Watts, 1991), were weak at P10. The completion of these VIP efferents may start transmission of SCN oscillation, and the multiple synaptic relay will convey these rhythms to the behavioral and hormonal centers. However, contrary to these rhythms, a pineal sympathetic rhythm was present by P4 (Moore, 1991), and a pineal enzyme $N$-acetyltransferase rhythm occurred from P4 to P7 (Duncan et al., 1986). This suggests that the SCN output pathway controlling the melatonin rhythm is different from those of other behavioral and corticosterone controlling systems.

In conclusion, we demonstrated that the phenotypic expression of main VIP neurons in the SCN appears at a late stage of development, although some rostral VIP traits were produced 
before birth. Moreover, in the study of the development of daily VIP mRNA rhythm, we found, unexpectedly, that the VIP mRNA rhythm was driven by an endogenous clock in the early developmental period. The endogenous rhythm generated by the earlier rostral group is gradually taken over by the light-dependent VIP rhythm generated later by the main group. These findings suggest that the mammalian circadian system occurs early in the fetal period and develops and performs environmental adaptation by differentiating a new cell group in the circadian pacemaking center, which integrates the information from environmental cues.

\section{REFERENCES}

Albers HE, Minamitani N, Stopa E, Ferris CF (1987) Light selectively alters vasoactive intestinal peptide and peptide histidine isoleucine immunoreactivity within the rat suprachiasmatic nucleus. Brain Res 437:189-192.

Albers HE, Stopa EG, Zoeller RT, Kauer JS, King JC, Fink JS, Mobtaker $\mathrm{H}$, Wolfe H (1990) Day-night variation in prepro vasoactive intestinal peptide/peptide histidine isoleucine mRNA within the rat suprachiasmatic nucleus. Mol Brain Res 7:85-89.

Altman J, Bayer SA (1978) Development of the diencephalon in the rat. I. Autoradiographic study of the time of origin and settling pattern of neurons of the hypothalamus. J Comp Neurol 182:945-972.

Amemiya Y, Miyahara J (1988) Imaging plate illuminates many fields. Nature 336:89-90.

Anderson DJ (1989) The neural crest cell lineage problem: neuropoiesis? Neuron 3:1-12.

Bosler O, Beaudet A (1985) VIP neurons as prime synaptic targets for serotonin afferents in rat suprachiasmatic nucleus: a combined radioautographic and immunocytochemical study. J Neurocytol 14:749-763.

Bunt SM, Lund RD, Land PW (1983) Prenatal development of the optic projection in albino and Hooded rats. Dev Brain Res 6:149-168.

Cagampang FRA, Inouye ST (1994) Circadian variation of argininevasopressin messenger RNA in the rat suprachiasmatic nucleus. Mol Brain Res 24:179-184.

Card JP, Brecha N, Karten HJ, Moore RY (1981) Immunocytochemical localization of vasoactive intestinal polypeptide-containing cells and processes in the suprachiasmatic nucleus of the rat: light and electron microscopic analysis. J Neurosci 1:1289-1303.

Duncan MJ, Banister MJ, Reppert SM (1986) Developmental appearance of light-dark entrainment in the rat. Brain Res 369:326-330.

Fukuhara C, Nishiwaki T, Cagampang FRA, Inouye S-IT (1994) Emergence of VIP rhythmicity following somatostatin depletion in the rat suprachiasmatic nucleus. Brain Res 645:343-346.

Glazer R, Gozes I (1994) Diurnal oscillation in vasoactive intestinal peptide gene expression independent of environmental light entraining. Brain Res 644:164-167.

Gozes I, Shani Y, Liu B, Burbach JPH (1989) Diurnal variation in vasoactive intestinal peptide messenger RNA in the suprachiasmatic nucleus of the rat. Neurosci Res Commun 5:83-86.

Güldner FH (1978) Synapses of optic nerve afferents in the rat suprachiasmatic nucleus. I. Identification, qualitative description, development and distribution. Cell Tissue Res 194:17-35.

Hares KA, Foster GA (1988) Immunohistochemical analysis of the ontogeny of peptide histidine isoleucine (PHI)-immunoreactive neurons in the pre- and postnatal rat brain. Brain Res 468:99-112.

Hendrickson AE, Wagoner N, Cowan WM (1972) An autoradiographic and electron microscopic study of retino-hypothalamic connections. Z Zellforsch Mikrosk Anat 135:1-26.

Hiroshige T, Honma K, Watanabe K (1982) Ontogeny of the circadian rhythm of plasma corticosterone in blind infantile rats. J Physiol (Lond) 325:493-506.

Hisano S, Chikamori-Aoyama M, Katoh S, Kagotani Y, Daikoku S, Chihara K (1988) Suprachiasmatic nucleus neurons immunoreactive for vasoactive intestinal polypeptide have synaptic contacts with axons immunoreactive for neuropeptide Y: an immunoelectron microscopic study in the rat. Neurosci Lett 88:145-150.

Honma S, Hiroshige T (1977) Pubertal manifestation of sex difference in circadian rhythm of corticotrophin-releasing activity in the rat hypothalamus. Acta Endocrinol (Copenh) 86:225-234.

Ibata Y, Takahashi Y, Okamura H, Kawakami F, Terubayashi H, Kubo T, Yanaihara N (1989) Vasoactive intestinal peptide (VIP)-like immuno- reactive neurons located in the rat suprachiasmatic nucleus receive a direct retinal projection. Neurosci Lett 97:1-5.

Ifft JD (1972) An autoradiographic study of the time of final division of neurons in rat hypothalamic nuclei. J Comp Neurol 144:193-204.

Inouye S-IT, Kawamura H (1979) Persistence of circadian rhythmicity in a hypothalamic "island" containing the suprachiasmatic nucleus. Proc Natl Acad Sci USA 76:5962-5966.

Inouye S-IT, Kawamura H (1982) Characteristics of a circadian pacemaker in the suprachiasmatic nucleus. J Comp Physiol (Lond) 146:153-160.

Ishikawa K, Frohman LA (1987) Ontogenesis of peptide-histidineisoleucine (PHI)-containing neurons in the suprachiasmatic nucleus (SCN) of the rat. Brain Res 407:144-147.

Kiss J, Leranth CS, Halasz B (1984) Serotoninergic endings on VIPneurons in the suprachiasmatic nucleus and on ACTH-neurons in the arcuate nucleus of the rat hypothalamus. A combination of high resolution autoradiography and electron microscopic immunocytochemistry. Neurosci Lett 44:119-124.

Laemle LK (1988) Vasoactive intestinal polypeptide (VIP)-like immunoreactivity in the suprachiasmatic nucleus of the perinatal rat. Dev Brain Res 41:308-312.

Lauder JM (1993) Neurotransmitters as growth regulatory signals. Trends Neurosci 16:233-240.

Lehman M, Silver R, Bittman EL (1991) Anatomy of suprachiasmatic nucleus grafts. In: Suprachiasmatic nucleus the mind's clock (Klein DC, Moore RY, Reppert SM, eds), pp 349-374. New York: Oxford UP.

Lenn NJ, Beebe B, Moore RY (1977) Postnatal development of the suprachiasmatic nucleus of the rat. Cell Tissue Res 178:463-475.

Meijer JH, Rietveld WJ (1989) Neurophysiology of the suprachiasmatic circadian pacemaker in rodents. Physiol Rev 69:671-707.

Moore RY (1983) Organization and function of a central nervous system circadian oscillator in the suprachiasmatic hypothalamic nucleus. Fed Proc 42:2783-2788.

Moore RY (1991) Development of the suprachiasmatic nucleus. In: Suprachiasmatic nucleus the mind's clock (Klein DC, Moore RY, Reppert SM, eds), pp 391-404. New York: Oxford UP.

Moore RY, Bernstein ME (1989) Synaptogenesis in the rat suprachiasmatic nucleus demonstrated by electron microscopy and synapsin 1 immunoreactivity. J Neurosci 9:2151-2162.

Moore RY, Lenn NJ (1972) A retinohypothalamic projection in the rat. J Comp Neurol 146:1-14.

Moore RY, Halaris AE, Jones BE (1978) Serotonin neurons of the midbrain raphe: ascending projections. J Comp Neurol 180:417-438.

Morin AJ, Denoroy L, Jouvet M (1991) Daily variations in concentration of vasoactive intestinal polypeptide immunoreactivity in discrete brain areas of the rat. Brain Res 538:136-140.

Nishizawa M, Hayakawa Y, Yanaihara N, Okamoto H (1985) Nucleotide sequence divergence and functional constraint in VIP precursor mRNA evolution between human and rat. FEBS Lett 183:55-59.

Okamoto S, Okamura H, Miyake M, Takahashi Y, Takagi S, Akagi Y, Fukui K, Okamoto H, Ibata Y (1991) A diurnal variation of vasoactive intestinal peptide (VIP) mRNA under a daily light-dark cycle in the rat suprachiasmatic nucleus. Histochemistry 95:525-528.

Okamura H, Ibata Y (1994) GRP-immunoreactivity shows a day-night difference in the suprachiasmatic nuclear soma and efferent fibers: comparison to VIP-immunoreactivity. Neurosci Lett 181:165-168.

Okamura H, Murakami S, Uda K, Sugano T, Takahashi Y, Yanaihara C, Yanaihara N, Ibata Y (1986) Coexistence of vasoactive intestinal peptide (VIP)-, peptide histidine isoleucine amide (PHI)-, and gastrin releasing peptide (GRP)-like immunoreactivity in neurons of the rat suprachiasmatic nucleus. Biomed Res 7:295-299.

Okamura H, Takahashi Y, Terubayashi H, Hamada S, Yanaihara N, Ibata Y (1987) VIP-like immunoreactive neurons and retinal projections in the rat suprachiasmatic nucleus. Biomed Res 8:253-262.

Okamura H, Kawakami F, Tamada Y, Geffard M, Nishiwaki T, Ibata Y, Inouye S-IT (1995) Circadian change of VIP mRNA in the rat suprachiasmatic nucleus following $p$-chlorophenylalanine (PCPA) treatment in constant darkness. Mol Brain Res 29:358-364.

Schwartz WJ, Davidsen L, Smith C (1980) In vivo metabolic activity of a putative circadian oscillator, the suprachiasmatic nucleus. J Comp Neurol 189:157-167.

Shinohara K, Tominaga K, Isobe Y, Inouye S-IT (1993) Photic regulation of peptides located in the ventrolateral subdivision of the suprachiasmatic nucleus of the rat: daily variations of vasoactive intestinal 
polypeptide, gastrin releasing peptide and neuropeptide Y. J Neurosci 13:793-800.

Shinohara K, Honma S, Katsuno Y, Abe H, Honma K (1994) Circadian rhythms in the release of vasoactive intestinal polypeptide and argininevasopressin in organotypic slice culture of rat suprachiasmatic nucleus. Neurosci Lett 170:183-186.

Silver R, Lehman MN, Gibson M, Gladstone WR, Bittman EL (1990) Dispersed cell suspensions of fetal SCN restore circadian rhythmicity in SCN-lesioned adult hamsters. Brain Res 525:45-58.

Swanson LW, Cowan WM, Jones EG (1974) An autoradiographic study of the efferent connections of the ventral geniculate nucleus in the albino rat and the cat. J Comp Neurol 156:143-164.

Takahashi K, Hanada K, Kobayashi K, Hayafuji C, Otani S, Takahashi Y (1979) Development of the circadian adrenocortical rhythm in rats: studied by determination of 24- or $48 \mathrm{hr}$ patterns of blood corticosterone levels in individual pups. Endocrinology 104:954-961.

Takahashi Y, Okamura H, Terubayashi H, Akagi Y, Hamada S, Fujita S, Yanaihara N, Ibata Y (1987) The influence of light stimulus on VIPlike immunoreactive neurons in the rat suprachiasmatic nucleus. Neurosci Lett 5:S92.

Takahashi Y, Okamura H, Yanaihara N, Hamada S, Fujita S, Ibata Y (1989) Vasoactive intestinal peptide immunoreactive neurons in the rat suprachiasmatic nucleus demonstrate diurnal variation. Brain Res 497:374-377.

Takatsuji K, Oyamada H, Tohyama M (1995) Postnatal development of substance $\mathrm{P}$-, neuropeptide $\mathrm{Y}$ - and serotonin-containing fibers in the rat suprachiasmatic nucleus in relation to development of retinohypothalamic projection. Dev Brain Res 84:261-270.

Tominaga K, Shinohara K, Otori Y, Fukuhara C, Inouye S-IT (1992) Circadian rhythms of vasopressin content in the suprachiasmatic nucleus of the rat. NeuroReport 3:809-812.

Watts AG (1991) The efferent projections of the suprachiasmatic nucleus: anatomical insights into the control of circadian rhythms. In: Suprachiasmatic nucleus the mind's clock (Klein DC, Moore RY, Reppert SM, eds), pp 77-106. New York: Oxford UP.

Watts AG, Swanson LW (1987) Efferent projections of the suprachiasmatic nucleus. II. Studies using retrograde transport of fluorescent dyes and simultaneous peptide immunohistochemistry in the rat. J Comp Neurol 258:230-252.

Watts AG, Swanson LW, Sanchez-Watts G (1987) Efferent projections of the suprachiasmatic nucleus. I. Studies using anterograde transport of Phaseolus vulgaris leucoagglutinin in the rat. J Comp Neurol 258:204-229.

Yanaihara N, Sakagami M, Sato H, Yamamoto K, Hashimoto T, Yanaihara C, Ito Z, Yamaguchi K, Abe K (1977) Immunological aspects of secretin, substance P, and VIP. Gastroenterology 72:803-810.

Yang J, Cagampang FRA, Nakayama Y, Inouye S-IT (1993) Vasoactive intestinal polypeptide precursor mRNA exhibits diurnal variation in the rat suprachiasmatic nucleus. Mol Brain Res 20:259-262. 